
Informations

une revue Gallia

Lorraine | 2001

\title{
Florange II
}

ZAC Sainte-Agathe II, bâtiment d'accueil

Marc Feller

\section{(2) OpenEdition}

Édition électronique

URL : http://journals.openedition.org/adlfi/9077

ISSN : 2114-0502

Éditeur

Ministère de la culture

Référence électronique

Marc Feller, «Florange II », ADLFI. Archéologie de la France - Informations [En ligne], Lorraine, mis en ligne le 01 mars 2001, consulté le 19 avril 2019. URL : http://journals.openedition.org/adlfi/9077

Ce document a été généré automatiquement le 19 avril 2019

(c) Ministère de la Culture et de la Communication, CNRS 


\title{
Florange II
}

\author{
ZAC Sainte-Agathe II, bâtiment d'accueil
}

\author{
Marc Feller
}

\section{Identifiant de l'opération archéologique : F1357200100044}

Date de l'opération : 2001 (SU)

1 À la suite d'un diagnostic réalisé en mai 2001 sur l'emprise d'un projet de bâtiment à usage tertiaire, une fouille de sauvetage a porté sur une petite nécropole du Iers. de notre ère. Après un décapage de $1400 \mathrm{~m}^{2}$, un ensemble de seize tombes à incinération concentrées sur $90 \mathrm{~m}^{2}$ a été mis en évidence.

2 La répartition topographique des structures funéraires montre un développement en arc de cercle. Plusieurs tombes ne contenaient qu'une simple urne avec les ossements du défunts alors que d'autres comportaient plusieurs pièces de vaisselle (plats, calices, assiettes). Il faut signaler au moins deux dépôts funéraires qui correspondent certainement à des tombes de l'élite locale. La tombe 1011 (Fig. n 1 : Dépôt funéraire, sépulture 1011) renfermait trois fioles en verre et une lampe à huile (tombe féminine? ); la tombe 1008 (Fig. n² : Dépôt funéraire, sépulture 1008) a livré deux cruches à piédouche avec décor en relief d'applique dont l'un conjugue un bouquetin associé à une palmette.

Chaque structure a été prélevée en motte afin d'en assurer le démontage en laboratoire. 


\section{ANNEXES}

Fig. $\mathrm{n}^{\circ} 1$ : Dépôt funéraire, sépulture 1011

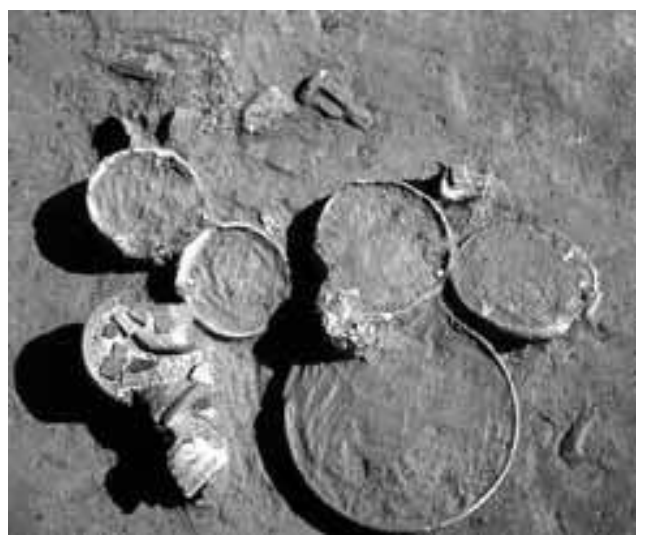

INRAP (2001)

Fig. $n^{\circ} 2$ : Dépôt funéraire, sépulture 1008

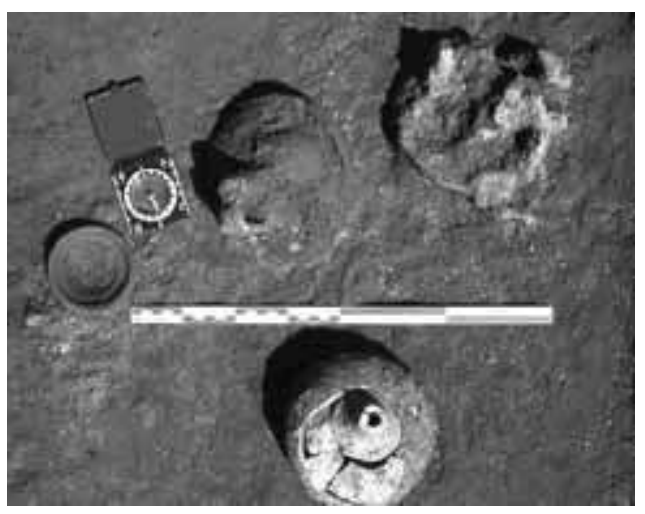

INRAP (2001)

\section{INDEX}

Index géographique : Lorraine, Moselle (57), Florange

Thèmes : calice, céramique gallo-romaine, dépôt funéraire, lampe romaine, nécropole à incinération, vaisselle, verrerie

operation Sauvetage urgent (SU)

Index chronologique : Empire romain

\section{AUTEURS}

\section{MARC FELLER}

